Conference Report

\title{
Hidden Suffering and the Effects of Adverse Childhood Experiences
}

\author{
William Fulford \\ Poulroe, Kilkeedy, Tubber, County Clare, Ireland; williamfulford@hotmail.com \\ Academic Editors: Fiona Timmins and Wilf McSherry \\ Received: 29 November 2016; Accepted: 15 February 2017; Published: 23 February 2017
}

\begin{abstract}
To understand suffering is to understand what it means to be human. Suffering focuses our attention on our vulnerability, which we would rather ignore or deny. As health care professionals (HCP) we need to be able to listen, to attune and be empathic to the suffering patient. If we act as an "enlightened witness" we provide a safe place for a suffering patient to grieve their loss and be vulnerable. This is skilled and demanding work, it is also important to tend to our own needs through a practice of self-care and reflection to prevent burn-out and compassion fatigue. The topic of adverse childhood experiences (ACE), which are common in the general population, are addressed in the second part of this paper. Their effects are profound, and increase with the degree of maltreatment. The maltreatment and suffering of these children usually remains hidden into adulthood beneath years of shame and denial. One aspect of our job in health care is to help patients acknowledge, experience, and bear the reality of life with all its pleasures and heartache. In order to do this well, we need to keep in touch with our own humanity, but also continue to take care of ourselves.
\end{abstract}

Keywords: suffering; meaning; healing; grieving; enlightened witness; spiritual; adverse childhood experiences; healthcare professional

\section{Avoiding Change}

When we see a nurse, or a doctor we want to be cured. We want them to remove, or correct our problem. A surgeon's knife cuts out an inflamed appendix. The patient is happy, she has survived, and her scar will not show on the beach. She returns to her family, friends, job, and all that makes up a life. She is essentially unchanged back to normal. We all like to be cured; we want to return to our regular life. We want to avoid change [1].

\section{Suffering and Loss}

In most human suffering, there is often nothing to see. We all suffer at some time or other in our lives; it is usually related to love or loss. We fall in love, we get rejected. As we move through our lives loved ones die, or dreams disappear. We feel it to the core of our being, if we can allow it.

Suffering is a state of distress associated with a symptom or an event that threatens our integrity [2]. We become fearful of the significance of a symptom, or how an event may affect our future. The perceived negative meaning may involve the actual or perceived loss of one's integrity or autonomy. The interpretation and the ensuing anxiety will be unique and personal even in an identical situation [3]. It is caused by the loss or threatened loss of what we most cherish [4]. To understand suffering is to appreciate what it is to be human. In contrast to pain, suffering is our experience of being cut off. No matter what we do, we have lost touch with our vital center, the deep well of our being. The loss of love or the life-altering implications of serious disease for instance, enforce change into our lives. How do we heal that suffering? 
In World War Two Victor Frankl, a young Jewish psychiatrist and his family were taken from Vienna, and incarcerated in the concentration camps. His mother and brother died in Auschwitz. His wife Tilly died in Belsen. His sister Stella and he were the only survivors. After the war he wrote about his experience. His book 'Man's Search for Meaning', sold 10 million copies until his death in 1997. In those camps he wrote,

'What was really needed was a fundamental change in our attitude to life. We had to learn ourselves, and furthermore, we had to teach the despairing men, that it did not really matter what we expected from life, but rather what life expected from us' ([5], pp. 76-77).

The intensity of suffering is a continuum extending from distress, through misery, to anguish and agony [4]. On any one day, we can have moments of being downcast by little disappointments (like missing a train), various frustrations (for instance being in a phone queue to an organization) and failures (making mistakes at work). At the other end of the spectrum may be the on-going anguish of being increasingly disabled and dependent for a patient in the advanced stages of Multiple Sclerosis. Or the agony of a parent losing a child in a road traffic accident.

Being separated from what we love is suffering; not getting what we want is suffering. Suffering puts us in touch with our vulnerability.

\section{Healing and Grieving}

We heal suffering through mourning, by slowly accepting, experiencing, and bearing the loss. The person, who suffers life-altering situations, goes through the same process of grieving as described by Elisabeth Kubler-Ross in her book Death and Dying. As a psychiatrist and palliative care physician, she spent her life working with dying people in America. The five stages of grief she describes in dying people are similar to any major loss [6].

(1) Denial "This can't be happening"

(2) Anger "Why me? It's not fair ..."

(3) Bargaining "I'll do anything if only ..."

(4) Depression "Why bother"

(5) Acceptance "It's going to be OK."

Ireland still uses ritual to honor and help lament the death of a loved one. However, generally in the Western world we are not encouraged to grieve our losses. We should be self-sufficient, not give in to the negative. We should keep our composure, be 'cool', be happy, be positive, and look on the bright side. However, how does it feel when we speak of our sorrow and a friend cuts us short, and tells us to be positive? Many have learned to keep their feelings always hidden, out of shame and fear of ridicule. It is indeed important to appreciate the good parts of our life, but it is also vital to allow ourselves sometimes to cry, and to mourn life's losses, in order to come to terms with things as they are.

The reality of life includes birth and death, joy and sadness, pleasure and heartache. Often, we may hold on too long because we cannot face the reality of inevitable loss, the slipping away of the old life and the old self. We often put our head in the sand through the short-term solace of an addiction. The pain of the loss then gets postponed and prolonged. We get better by acknowledging, feeling and enduring the reality of our loss. We need to peer into the deep well of our being, explore what we know, and actually feel what we feel [7]. Then the tears and laughter can surface, but we need plenty of time and space to get to know them. We might also need to share our suffering with a friend or relative or perhaps seek some professional help to understand what burdens us.

\section{The Enlightened Witness}

Alice Miller, the Swiss psychologist talks of the need of the "enlightened witness" especially for victims of childhood maltreatment [8]. An enlightened witness can help these silently suffering people feel seen and accepted despite hiding their shameful secrets for years [9]. 
Healthcare professionals also of course have episodes of life-altering suffering. I went through a dark time 25 years ago, during and after a divorce. Fortunately, I was able to ask for help. Two friends were my "enlightened witnesses", they listened and accepted me. They did not lecture me, but believed in me and my intrinsic goodness. I slowly moved with their help to the other side of mourning. Looking back that episode in my life helped me move from being one of the "walking wounded" to being a "wounded healer" [10]. If we are able to transform our own woundedness we are then able to be more present with our patients suffering [11].

Quoting Goethe, the German poet, "Our suffering prepares us to appreciate the suffering of others".

\section{Suffering and Meaning}

The fabric of our lives, our relationships, our home, our work, our spiritual beliefs, and many activities help to give it meaning. Our integrity and identity is threatened if we lose one or more of these structures from our life. The comfort of our routine is stripped away by the pain of loss. We suffer because we are unable to make peace with the reality of our new situation. The everyday now seems meaningless-meaning has been taken away from us.

In this lonely place, we are forced to start looking for meaning and hope. As we question ourselves we start to realize what is important to us. We slowly learn to be with ourselves more deeply. We discover parts of ourselves that were previously hidden. In the searching and suffering something slowly changes in the depths of our soul. We become deeper, more spiritual. Our suffering ceases to be suffering in some way at the moment it finds meaning ([5], p. 133). The wound starts to heal and we can begin to make peace with what is.

\section{Being Heard and Accepted}

Even though I'm a doctor, part of me is also a patient. The word "patient" comes from the Latin 'patiens' which means 'one who suffers'. We are all patients.

When we suffer, we sometimes feel undeserving and become withdrawn [9]. We look down, we stare at our feet. We give out mixed signals. Leave me alone. No, do not go. In our inner confusion, we often do not know what we want. What do we need?

The most valuable thing we can give each other is our genuine interest, our warmth and our undivided attention. "Being heard and accepted" goes far beyond any problem-solving or intellectual understanding of our plight [12].

If we pay heed to the sufferer and are fully present for them, is it possible that they may begin to recognize their own value? If they are allowed to relate their story, could they begin to reflect on, redefine, and perhaps finally transcend their suffering? There is a distress in not telling our untold story. We can aggravate or prolong this suffering by walking away, or by ignoring the stories that need to be told.

Moreover, if it is we who are suffering, we might need to take a risk, be vulnerable, tell our story, reveal ourselves more fully, and be seen for who we are.

For some of us our suffering may be our first ever contact with the spiritual dimension of our life. We are forced to reflect deeply on the fabric of our lives and search for new meaning that will sustain our future. Elisabeth Kubler-Ross says "Nothing is a faster teacher than suffering. The more we suffer, the earlier the spiritual quadrant opens and matures" [12].

\section{Paired Opposites}

Sometimes we feel strong, sometimes we feel vulnerable. However, one way or another we need each other, often we cannot admit it.

A doctor needs a patient. Without a patient, he cannot perform his role as a doctor. A sick person might need a doctor, and when she does she becomes a patient. Doctor and patient are an opposing pair, each with their own role. They are equivalent to a husband and wife or a mother and child. 
In their roles, the two poles of a pair owe their existence to their interdependence. The ebb and flow between these pairs helps them to define their role more clearly.

When we are sick we sometimes feel out of control, perhaps fearful of our symptoms, especially in the middle of the night. 'I've had this awful headache for three days. Maybe I've got a brain tumor; I'll make an appointment to see the doctor in the morning?' We become a patient when we seek the expertise of a doctor. We hope she will allay our fears and solve our problem. The suffering patient in their vulnerability becomes in part child-like and dependent. This in turn affects the doctor who then feels powerful and strong.

If this pattern continues repeatedly over years without self-awareness, the balance of power between the paired opposites can become unbalanced ([13], p. 92). The doctor, too identified with the feeling of power, can begin to lose his vulnerability, his humanity. He can appear arrogant, treating patients and staff as weak and ignorant, inferior mortals.

I worked in one practice many years ago; an older GP would occasionally pick up a ringing phone as he rushed through the reception area. "God here, how can I help you?"

\section{Reliance and Resilience}

Our lives are shaped through love and loss as long as we live. The most critical time in our development is early childhood. Yet not all children suffer lasting harm as a result of childhood maltreatment, some show resilience in response to serious hardship.

The Centre on the Developing Child at Harvard University have written about the factors that enable resilience despite early adversity [14]. They state that whether these children have endured abuse, neglect, or a dysfunctional household, the single most common finding is that children who end up well have had at least one stable and committed relationship with a supportive parent, caregiver or other adult. These relationships are essential to children developing key qualities, such as being able to plan, to be aware of and regulate their feelings and behavior. They are then more able to adapt to changing circumstances, when difficulties arise they are better able to cope with them [15].

\section{Adverse Childhood Experiences}

The more adverse childhood experiences (ACE) we have suffered, the greater the effect it will have on our entire lives [16,17]. The first long-term longitudinal study of ACEs was started in 1995 in San Diego, California by Dr Vincent Felitti, of Kaiser Permanente Insurance and Dr Robert Anda from the US department of Public Health ([18], pp. 77-88). They studied 17,000 people who were enrolled with the health insurance company. They were predominantly well-educated and middle-class.

Doctors Felitti and Anda realized the importance of ACEs, and included questions about them as part of a health questionnaire. People filled out their forms at home, and then brought them to their yearly medical. There are three main areas of childhood maltreatment- abuse, neglect and household dysfunction.

As their study developed they defined 10 categories of ACE. The percentages noted in each of the 10 categories are the percentage that were affected within the whole study group.

Abuse:

(1) Emotional: recurrent threats, humiliation (11\%)

(2) Physical: beating not spanking (28\%)

(3) Contact sexual abuse ( $28 \%$ women, $16 \%$ men- $22 \%$ overall)

Neglect:

(4) Physical (10\%)

(5) Emotional (15\%) 
Household Dysfunction

(6) Mother treated violently (13\%)

(7) Household member was alcoholic or drug user (27\%)

(8) Household member was imprisoned (6\%)

(9) Household member chronically depressed, suicidal, mentally ill, or in psychiatric hospital (17\%)

(10) Parental Divorce or Separation (23\%)

They found that ACEs were common even in this middle class, well-off population. More than 1 in 4 grew up with an alcoholic or drug user, and two-thirds had experienced at least one ACE. If they were affected by two categories of ACE they would have an ACE score of 2. More than 1 in 10 had an ACE score of 5 or more of these categories, so $10 \%$ of the 17,000 , that is 1700 people, had been subjected to five or more of these categories of childhood maltreatment.

ACEs occur in clusters, so if one ACE is present, it is worth asking whether others are also present. If children are surrounded by alcohol abuse in the home, there is an increased chance they are being subjected to other types of maltreatment.

Every day every doctor in General Practice will see several patients with high ACE scores, but they will not usually disclose or be asked about their childhood experiences. One common presentation is that they often complain of unexplainable symptoms. Felitti and Anda found a relationship between the likelihood of past sexual abuse and the number of unexplained symptoms ([18], p. 77). Adults with numerous ACEs often show difficulties in emotional and social competence with a tendency to high levels of anxiety and hostility. Typically, they will be experienced as the most difficult patients of the day.

We've all had experience of difficult patients; they are difficult for a reason. As young children, they found their own way to protect themselves and their vulnerability from the abuse and maltreatment they were subjected to. They were dependent and poorly cared for; they could not leave, unless they were taken into care.

Over the years as we reach adulthood our ACEs become shrouded in dust. The suffering is hidden, rarely discussed because of shame, secrecy, amnesia and denial ([18], p. 77). However, as Dr Felitti and Anda point out the effect of these earliest years are not lost, like a child's footprint in wet concrete they often persist throughout a lifetime ([18], p. 80).

In their ACE study they found that as the ACE score increases, so do the risks of numerous health and social problems throughout a lifespan. I will use just two examples to illustrate this point. Male children with an ACE score of 6 or more are 46 times more likely to become an injection drug user compared to a male child with an ACE score of 0 ([18], p. 82). Also, if you had a ACE score of 6 or more your life span is 20 years shorter than if you had a score of 0 . They usually do not live beyond sixty, and die from a variety of causes [17].

Observations in the psychotherapy literature suggest many people are attracted to the helping professions through their childhood experiences of woundedness [19,20]. Did the little helper grow up to be a professional carer? Despite a wide literature search, I found nothing on the prevalence of ACEs in healthcare professionals. I found one study however from social work on their prevalence in child service providers [21]. They found that $53 \%$ of their group had an ACE score of 2 or more, compared to the original San Diego ACE study which had 38\%. In their study the commonest ACE category was growing up with a family member suffering from chronic depression or mental illness; this was experienced by $34 \%$ of the study group. The researchers suggest this might have influenced their choice of a social work career.

Recently (six months after the conference) I found a paper on the prevalence of childhood adversity among healthcare workers (mainly nurses in a Canadian Hospital) and its relationship to adult life events, distress, and impairment [22]. They found $68 \%$ of their 176 healthcare workers had one or more experiences of violence, abuse, or neglect, $33 \%$ before the age of 13 . This group experienced more psychological distress and a higher number of stressful life events. 
If we generalize the results of the large San Diego ACE study with its cohort of well- educated and financially comfortable people, there is every chance that a quarter of us reading this paper (with a similar background) will have grown up with an alcoholic or drug user. One in five of us will have grown up with a household member who was chronically depressed or mentally ill.

\section{Burnout and Self-Care}

While the early wounds and suffering of childhood may enable healthcare professionals to be more empathic with their patients, they may also increase the risk of compassion fatigue and burn-out [22,23].

Our role as healthcare professionals is both an honor and a privilege, yet it can affect our well-being. The long hours, lack of sleep, the isolation from friends and family, the stress and responsibility of caring for sick patients can cause some to burnout. Burnout is defined as emotional exhaustion, depersonalization, (i.e., treating patients as objects), and feelings of worthlessness [24].

Healthcare professionals being usually identified with being strong and efficient are reluctant to admit to any weakness or vulnerability [24]. They project their suffering on to their patients. They treat patients, they do not identify with being a patient themselves ([13], p. 94; [20]). Sometimes the lives of healthcare professionals get so out of balance through caring too much for others and not caring enough for themselves that they become sick and burnout [25]. An inversion has occurred; they now occupy the role of the patient.

Up to $60 \%$ of practicing primary care physicians in the US report symptoms of burnout [26]. Nursing is a high stress career. In one recent study in the UK, the stress score for nurses was one and a half times higher than the average for soldiers after a military trauma in a warzone [27]. In the same study the level of burnout was also found to be exceedingly high [28].

When we are extremely stressed we feel unsafe: we tend to react to situations, feel angry or get defensive. Our ability to think clearly and reason is reduced. We become unreasonable. In contrast when we are working at our best, we are alert, open and curious. We are self-aware, able to think and feel simultaneously $[29,30]$. Our reactions adapt to fit the situation. We are in the zone; we enjoy what we are doing, and feel safe enough to be creative, spontaneous, and humorous.

A mindful awareness can help develop a kind, objective, witnessing attitude to ourselves, a self-compassion. If we are suffering, we often feel a sense of isolation. A spiritual practice can help connect us to an ultimate sense of meaning, a reality greater than ourselves. Regular meditation, breathing, and other forms of self-care help us create an inner calm. They also improve our ability at both recognizing our stress levels and regulating them [25]. We are then more able to think clearly, stay in the zone, and enjoy being a nurse or a doctor. Sometimes we are so stressed we cannot see the wood for the trees. We might need to give ourselves some time out for reflection, or ask for support from the people we trust, or perhaps seek professional help. This may help us to see the influence of earlier life events on our situation, and to recognize where personal and professional changes are needed. We might need to set limits on work and work hours, and clearly separate the professional from the personal.

Maybe we should do what we tell our patients to do. Eat healthily. Exercise. Take a break. Enjoy ourselves, our family, and our friends.

We teach, what we most have to learn.

But the better we are able to care for ourselves.

The better we are able to care for others, and enjoy it.

One golden rule I try to keep, is to treat others, like I would like to be treated myself.

And I am also slowly learning, to treat myself with the compassion, I usually reserve for others.

I think being human and being truly present with our patients is often more healing than many of the technical aspects of our jobs.

I believe the more we are able to accept and transform our own experiences of suffering, the more present we are to others' suffering. 
We are then more able to accompany patients and others, as they heal and become more whole.

May you have the commitment

To know what has hurt you,

To allow it to come close to you,

And in the end, become one with you. Gaelic Blessing [4].

Conflicts of Interest: The author declares no conflict of interest.

\section{References}

1. Hutchinson, Tom A., Nora Hutchinson, and Antonia Arnaert. "Whole Person Care: Encompassing the two faces of Medicine." Canadian Medical Association 180 (2007): 845-46. [CrossRef] [PubMed]

2. Cassel, Eric J. The Nature of Suffering and the Goals of Medicine. Oxford: Oxford University Press, 1991, p. 33.

3. Cassel, Eric J. “Diagnosing Suffering: A Perspective." Annals of Internal Medicine 131 (1999): 531-34. [CrossRef]

4. Kearsley, John H. "Therapeutic Use of Self and the Relief of Suffering." Cancer Forum 34 (2010): 1-4.

5. Frankl, Viktor E. Man's Search for Meaning. Boston: Beacon Press, 2006.

6. Murphy, Paul, and Lori Lind. "Healing Suffering: A Clinical Pastoral Response to Suffering. National Association of Catholic Chaplains Conference May 2014." Available online: https:/ /www.nacc.org/docs/ conference/2014/P2\%20-\%20Healing\%20Suffering\%20Presentation.pdf (accessed on 24 November 2016).

7. Van der Kolk, Bessel. The Body Keeps the Score. Mind, Brain, and Body in the Transformation of Trauma. London: Allen Lane, 2014, pp. 26-27.

8. Miller, Alice. The Body Never Lies. New York and London: W. W. Norton, 2005, p. 23.

9. Melvin, Christina S., and Barbara S. Heater. "Suffering and Chronic Sorrow: Characteristics and a Paradigm for Nursing Interventions." International Journal of Human Caring 8 (2004): 41-47.

10. Christie, Wanda, and Sara Jones. "Lateral Violence in Nursing and the Theory of the Nurse as Wounded Healer." Online Journal of Issues in Nursing 19 (2014): 2-3.

11. Kearney, Michael. A Place of Healing. Working with Suffering in Living and Dying. Oxford: Oxford University Press, 2000, pp. 99-100.

12. Egnew, Thomas R. "The Meaning of Healing: Transcending Suffering." Annals of Family Medicine 3 (2005): 255-62. [CrossRef] [PubMed]

13. Guggenbuhl-Craig, Adolf. Power in the Helping Professions. Dallas: Spring, 1971.

14. Center of the Developing Child at Harvard University. "Resilience." Available online: https://www. developingchild.harvard.edu/science/key-concepts/resilience (accessed on 22 April 2016).

15. Center of the Developing Child at Harvard University. "Supportive Relationships and Active Skill-Building Strengthen the Foundations of Resilience. Working Paper 13." Available online: http://developingchild. harvard.edu/wp-content/uploads/2015/05/The-Science-of-Resilience.pdf (accessed on 24 November 2016).

16. Brown, David W., Robert F. Anda, Henning Tiemeier, Vincent J. Felitti, Valerie J. Edwards, Janet B. Croft, and Wayne H. Giles. "Adverse Childhood Experiences and the risk of mortality." American Journal of Preventative Medicine 37 (2009): 389-96. [CrossRef] [PubMed]

17. McCrory, Cathal, Cara Dooley, Richard Layte, and Rose Anne Kenny. "The lasting legacy of childhood adversity for disease risk in later life." Health Psychology 34 (2015): 687-96. [CrossRef] [PubMed]

18. Felitti, Vincent J., and Robert F. Anda. "The Relationship of Adverse Childhood Experiences to Adult Medical Disease, Psychiatric Disorders, and Sexual Behavior: Implications for Healthcare." In The Hidden Epidemic: The Impact of Early Life Trauma on Health and Disease, 1st ed. Edited by Ruth A. Lanius and Eric Vermetten. Cambridge: Cambridge University Press, 2010, pp. 77-88.

19. Barnett, Marilyn. "What Brings You Here? An Exploration of the unconscious motivations of those who choose to train and work as psychotherapists and counsellors." Psychodynamic Practice 13 (2007): 257-74. [CrossRef]

20. Zerubavel, Noga, and Margaret O'Dougherty Wright. "The Dilemma of the Wounded Healer." Psychotherapy 49 (2012): 482-91. [CrossRef] [PubMed] 
21. Esaki, Nina, and Heather Larkin. "Prevalence and Adverse Childhood Experiences (ACEs) Among Child Service Providers." Journal of Contemporary Social Services 94 (2013): 31-37. [CrossRef]

22. Maunder, Robert G., Nathalie Peladeau, Diane Savage, and William J. Lancee. "The prevalence of childhood adversity among healthcare workers and its relationship to adult life events, distress, and impairment." Child Abuse and Neglect 34 (2010): 114-23. [CrossRef] [PubMed]

23. Nelson-Gardell, Debra, and Deneen Harris. "Child abuse history, secondary traumatic stress, and child welfare workers." Child Welfare 82 (2003): 5-26. [PubMed]

24. Beresin, Eugene V., Tracey A. Milligan, Richard Balon, John H. Coverdale, Alan K. Louie, and Laura Weiss Roberts. "Physician Wellbeing: A Critical Deficiency in Resilience Education and Training." Academic Psychiatry 40 (2016): 9-12. [CrossRef] [PubMed]

25. Kearney, Michael K., Radhule B. Weininger, Mary L. S. Vachon, Richard L. Harrison, and Balfour M. Mount. "Self-care of physicians caring for patients at the end of life." Journal of American Medical Association 301 (2009): 1155-64. [CrossRef] [PubMed]

26. Krasner, Michael S., Ronald M. Epstein, Howard Beckman, Anthony L. Suchman, Benjamin Chapman, Christopher J. Mooney, and Timothy E. Quill. "Association of an Educational Program in Mindful Communication with Burnout, Empathy, and Attitudes among Primary Care Physicians." JAMA 302 (2009): 1284-93. [CrossRef] [PubMed]

27. Calkin, Sarah. "Nurses more stressed than combat troops." Nursing Times, 15 January 2013. Available online: https://www.nursingtimes.net/roles/nurse-managers/nurses-more-stressed-than-combattroops/5053522.article (accessed on 24 November 2016).

28. Wallbank, Sonya. "Maintaining professional resilience through group restorative supervision." Community Practitioner 86 (2013): 23-25. [PubMed]

29. Ogden, Pat, Kekuni Minton, and Clare Pain. Trauma and the Body. A Sensorimotor Approach to Psychotherapy. New York and London: W.W. Norton and Co., 2006, p. 27.

30. Siegel, Daniel J. Mindsight. Oxford: Oneworld Publications, 2010, p. 137.

(C) 2017 by the author. Licensee MDPI, Basel, Switzerland. This article is an open access article distributed under the terms and conditions of the Creative Commons Attribution (CC BY) license (http:/ / creativecommons.org/licenses/by/4.0/). 